himself short-sighted, and desires to employ the direct method, he must be supplied with that concave ocular which will precisely neutralise his own defect.

Before I leave the subject of the mere management of the instrument, and proceed to describe what it reveals, I ought to mention that the object-lens should always be held a little obliquely. If it be perpendicular to the course of the light, it will return a reflected image of the mirror from each surface. By giving it a slight obliquity, these reflected images will be moved in opposite directions, and the details of the fundus will be seen between them.

\section{ON THE DIFFUSION OF SCARLET FEVER, AND ITS ARREST.}

\author{
BY JOHN W. OGLE, M.D., \\ PHYsiciat to st. GRoRGE's Hospital.
}

THE alarmingly increasing proportions which scarlet fever is assuming in this country not only, I venture to think, justifies, but imperatively calls for, the relation of any facts which may even remotely tend to fix attention upon the numerous channels of its communication, or may give rise to suggestions respecting means for its abatement. I trust that the following facts which I shall record, all of which have more or less directly come within my personal knowledge, may be considered pertinent. The first two cases go far to show how people may be fully alive to the necessity of taking all precautions in preventing infection, and yet use means which are inadequate.

A short time ago I was asked to visit a girl aged about fifteen who was dying of scarlet fever. Upon inquiry her history proved to be as follows. She was the surviving sister of four brothers and sisters, all of whom had died of scarlet fever three months previously in the same house wherein she was lying. On the occasion of their death, it appears that the father and mother-very well-to-do people - had taken all the means they could think of for purifying the house : the furniture had all been scrubbed and cleaned with carbolic-acid solution, and the bedding and clothing of all kinds properly cleansed; the walls stripped, re-covered, and painted, \&e. The parents left the house empty, and went with their only girl to Brighton for ten weeks, partly with a view to prevent subsequent infection, and partly out of a natural dislike to return too soon to the scene of so much disaster and unhappiness. They then returned home, and in rather more than a fortnight the remaining child sickened with scarlet fever, and the attack was so rapid and severe that she succumbed in spite of all assistance. On examining into the precautions taken to prevent such infection as had occurred, we could not for some time comprehend how this girl could have taken the disease, until we found out that, in the universal cleansing, two large oldfashioned arm-chairs existed in the sick room with hair cuskions and backs, the outer coverings of which were much tattered, allowing the hair to protrude in various places; and these cushions had, by some oversight, not been emptied and replenished. Thus there seemed every probability that the loose hair hanging from these dilapidated cushions and floating about had been the nidus for the spread of infection.

In the second case of oversight as to preventive measures which not lons since came under my notice, all care during convalescence was supposed to have been taken, when, after an interval, the disease again appeared, apparently in consequence of a single article of clothing which had been left hidden in a drawer that had not been cleaned out.

The following cases show how egregiously careless people are apt to be in this matter of infection, as if recklessly ignoring its existence. A little child is now under my care at St. George's Hospital who was admitted with dropsy of the whole bods, and acute inflammation of the kidneys, passing a large amount of blood from those organs. It proved, on inquiry, that she had been ill a month of scarlet fever, and that until this bloody urine came on she had actually been allowed to go day by day to school, throughout the extremely cold and foggy weather which we have been having, and permitted to mix with her fellow school children, not being kept at home a single day throughout the conrse of the fever and the peeling of the skin which followed; the friends and schoolmistress considering it only a case of scarlatina, and, as the mother said, "not worse than a cold.".*

This very day, again, I have investigated the case of a boy who canght scarlet fever under the following circumstances:-He was living as servant in a respectable family, several members of which had scarlet fever. He was himself taken ill, and for an entire week, whilst ill and vomiting from time to time, was kept daily at his work, cleaning boots and shoes, scrubbing the outside steps in this inclement weather; his friends, who lived near, not being communicated with until he was sent home prostrate to his mother, in a state of delirium, which has now been going on for four days.

I may here mention that I have known a case of scarlet fever in which the infection appeared undoubtedly transmitted in some small woollen patterns sent by post from an infected family; and within the last month a lady told me that a poor woman in her neighbourhood recently received a letter which had been allowed to be written and forwarded by a friend suffering at the time from small-pox in one of our public institutions. A short time a go a lady informed me that she had been calling with one of her children upon another lady, was shown into her room, and after half an hour's conversation the lady said: "By-the-bye, perhaps I ought to have asked the servant to have told you that our children have scarlet fever, as you might not like to stop very long." The little patients were in the adjoining room behind the folding doors all the time. I need not say that the morning visit was not prolonged.

Some facts have recently been recorded tending to show that the laundry may be the agency of infection, the clothes of the sick being washed at the same time and in the same tubs as those of other people. Of course under any circumstances this ought not to be; but I would suggest that, even should this promiscuous washing occur, if the suspected clothes were well boiled-i. e., submitted to the temperature of $212^{\circ}$ (even if they had not been immersed in some suitable disinfectant, as assuredly such clothes should always be, before removal from the bed room), all chance of infection would be destroyed.

But there is another way in which newly-washed clothes may become a means of propagation of scarlet fever and other like diseases, and that is by their being dried and "aired" (as they must needs be very frequently in large towns) in the rooms of washerwomen. Dr. R. Thompson, of the Brompton Hospital, informs me that he has himself seen a young man covered with the eruption of small-pox in a room, from the ceiling of which several articles of clothing which had just been washed were suspended in the drying process.

But perhaps one of the saddest modes of contracting infection is when people go in search of health to some seaside or watering-place, and are plunged in an atmosphere of infection by lodging in houses or rooms inhabited but recently by fever-stricken patients, and not yet duly purified. In many instances it is possible that the lodging-house keepers may be ignorant of the gravity of the matter, and think that their slender efforts, consisting of the use of a little whitewash and soap, are all-sufficient for thorough disinfection. But whatever may be the explanation in some cases, I have known of several well-marked outbreaks of scarlet fever contracted by lodging in apartments lately tenanted by sufferers from that affection.

The following case, for which my informant, a practical and intelligent gentleman, vouches, is a most painful example of culpable acquisitiveness, which might have led to important consequences. A person went to a wateringplace two summers ago, intending to procure lodgings. The place was crowded, and after difficulty he found one house where he was told he could have accommodation, but that he must wait until evening, as the "party" occupying the rooms was going out, but could not leave until late in the

* I am fully persuaded that much harm is done by the use of the worc scarlatina, Among the public mans suppose it stands for quite a different disease from the infectious scarlet fever; others think it at any rate import a very mild and innocuous variety of the disease. Thus are thes led to $b$ wanting in care towards those suffering from the disease. Even medical men unwittingly lend themselves to this fallacy very often, by using the word in relation to slighter cases, with the view of allaying apprehensions on the part of friends. 
afternoon. Pleased to make this arpangement, he sauntered out, and accidentally met a friend who was staying in the place, and to whom he related his good fortune. His friend inquiring as to the house where he had secured lodgings, at once recognised it as one said to contain inmates dangerously ill with scarlet fever. This statement of course led to further investigation, and it turned out indeed that so it was; and that, moreover, the "party" described as being about to vacate for the new-comer was no other than a dead man who was to be carried forth to his burial, a victim to the fever.

'The same gentleman, this year, being at the seaside, was strolling out with his landlord, when he directed his attention to a house where several lodgers lay ill with scarlet fever. They were, however, convalescent, and about to remove. When asked by my friend how long it would requile to make the lodgings again habitable, he told him they would all be ready for new visitors in twenty-four hours. "But," said my friend, "can the medical man in attendance allow that?" The reply was, "Ah, that is his business, not mine. Besides, to whom could he apply on the matter?"

The facts I have briefly related above-and I could recount others of a like kind, did space permit-speak for themselves; and, being simply such as the experience of daily medical life has casually afforded, I doubt not that, if anything like strict inquiry were made, every medical man would be able to supply numerous instances of an equally instructive and painful character.

If this be so, ind if in every town and village the same culpable negligence is being constantly repeated, how readily may we account for the overpowering vigour which this plague appears to have acquired in our country, and for the increase of area which it seems to cover, no Phinehas standing up to stay its progress. It must be borne in mind that the strength and virulence of the disease must be estimated not merely from the number of deaths reported by our registrars, but also from the dropsies, the affections of the kidneys and of the glandular system, the permanent shattering of the general constitution, and the proclivity to numerous secondary disorders, entailed by the disease.

It appears necessary that the public should recognise, and realise more strongly and definitely, the various channels by which the disease appears to be communicated; and if it is to be arrested, or even checked, with anything like an approach to completeness, some species of "stamping out" must be resorted to, and measures as stringent as the liberty of the subject will permit to be entertained must be devised by the powers that be, for the protection of the public. I would therefore venture to make the following suggestions :-

1. That it should be rendered compulsory for every householder or medical man to make a report of every case of contagious disease to some recognised anthority-either to the ordinary medical inspector of health, if such exists in the district, or to some medical man who should be appointed inspector for the purpose. This should be done, of course, whether the case be among the rich or the poor.

2. That, acting on this information, the duty of the inspector should be to enforce a system or code of proper precautionary measures for the avoidance of the extension of the disease (the details of such a system to be approved by the Medical Department of the Privy Council). Where money and appliances existed, the precautionary scheme would readily and quickly be carried out by friends; but when cases occurred either in the upper or middle classes, in families whose household arrangements are such as not to permit of its execution, but who are able to pay for care and medical attention, then the patients should be removed to " retreats." Hence I would suggest-

3. That proper "retreats" or "sanatoria" should beprovided in some convenient place outside the town, properly segregated, and surrounded by open ground or gardens, probably worked by private speculation (and a very lucrative one I believe this would be to such medical men as would undertake them), but under the general watching of the before-named inspector. Patients in such sanatoria should of course be attended, if required, by their own medical men, but in very many instances most probably families would be content with the services of the resident medical attendants. For the indigent, the hospitals or infirmaries provided by the Poor-law Board would be the proper recep- tacles; and parishes and unions would seem to have as much need of sanatoria for scarlet ferer (and that a tolerably constant one) as lately they had for relapsing fever."

4. I would suggest that scarlet fever cases should not be capable of admission into any of our general hospitals (any more than small-pox) until the desquamating stage is past; unless provision be made for their isolation in some part of the building deroted to their reception, and provided with all appliances requisite for the treatment of such cases, for which special nurses should exist, having as little communication as possible with the institution at large. I make this sugrestion by reason of the frequent communication which occurs in our hospitals of the disease from scarlet fever patients to their neighbours, even to surgical patients, which sometimes proves fatal; also on account of the danger of infection which is incurred by the great number of promiscuous visitors, often young children, who come daily into our hospital wards, and hang about the beds of patients, whom they play with and amuse, handling their books and clothing, pocket-handkerchiefs, toys, \&c. And this danger is not confined to the visitors, but extends to their families at home, to whom they may undoubtedly, by means of fomites, transfer infection, without themselves being the subjects of the disease.

I have satisfactory reason for saying that patients free from scarlet fever in our hospitals may, by exposure to the poison in the wards, carry it out with them, and subsequently die of it; although they may themselves leave the hospital apparently in perfect health. I have personal knowledge of such a case.

I have above alluded to the culpability of lodging-house keepers admitting families into apartments without informing them that cases of infectious disease had lately inhabited them. I would conclude by suggesting the importance of our having positive knowledge as to what the law says on that point. Are such people generally amenable to law for such conduct? Is it penal?-or does it only come within the law in certain localities, according to the working of certain Health Acts? I cannot help thinking that a full statement and understanding of the law on this point would be of great service to the profession and to the public.

November $24 t h, 1870$.

\section{INDIAN BOILS; THEIR VARIETIES AND TREATMENT.}

\section{BI JAMES C. DICKINSON,} IATE BENGAI MEDICAL SERYICH.

$$
\text { (Concluded from p. 813.) }
$$

DELHr BoILs, like their congeners the Gwalior ulcer and Scinde boil, derive their name from the locality in which they are endemic, although by the natives they are frequently called "Aurungezebe," on account of the Emperor of Delhi of that name having suffered from them. When it is remembered that there are numerous instances on record where whole regiments, both European and native, have been totally disabled for all military duties, together with the fact that the practice or treatment adopted has either been only partially narrated, or at least is only to be found scattered among Indian publications, many of which had a mere ephemeral existence, a consideration of the subject-the causes, diagnosis, and treatment-will not be altogether profitless, and possibly may attract the attention of practitioners who intend to follow an Indian career.

By some the Delhi boil is spoken of as an "ulcer." This is hardly precise, inasmuch as the ulcerative stage is simply the result of the unchecked inflammatory one. The characteristics of the Delhi boil are as follows; and, en parenthese, I venture to believe the description to be truthful, inasmuch as $I$ myself have been a great sufferer from them in 1864 and 1865, during $\mathrm{my}$ residence at Delhi and its neighbourhood.

In the first stage the Delhi boil is nothing more than a

* Such sanatoria are found most useful in the case of our Iarge public schools. Why should not our universities also possess them? It has, how"declare" any cases of infectious disease which occur in their lodgings.
"doty 